\title{
Novel Straight Type Aortic Cannula with Spiral Flow Inducing Design
}

\author{
NOFRIZALIDRIS DARLIS ${ }^{1, a}$, NADIA SHAIRA SHAFII ${ }^{2, b}$, \\ JESWANT DILLON ${ }^{3, \mathrm{c}}$, KAHAR OSMAN ${ }^{1,2, \mathrm{~d}}$, \\ AHMAD ZAHRAN MD KHUDZARI ${ }^{2, \mathrm{e}}$ \\ ${ }^{1}$ Faculty of Mechanical Engineering, \\ ${ }^{2}$ IJN - UTM Cardiovascular Engineering Center, Faculty of Biosciences and Medical Engineering, \\ Universiti Teknologi Malaysia, \\ 81310 Skudai, Johor, MALAYSIA \\ ${ }^{3}$ Institut Jantung Negara (IJN), Kuala Lumpur, Malaysia \\ anofrizalidris@yahoo.com, bnaddyshaira@yahoo.com, cjeswant@ijn.com.my, \\ dkahar@fkm.utm.com.my ${ }^{\mathrm{e}} \mathrm{zahran@biomedical.utm.my}$
}

Keywords: Spiral flow, aortic cannula design, arterial cannulation, cardiopulmonary bypass, computational fluid dynamics.

\begin{abstract}
Aortic cannula is one of major factors leading to adverse events such as thrombosis and atherosclerosis development during open heart surgery, due to oxygenated blood outflow with high velocity jet from heart lung machine (HLM) when exiting the cannula tip into the ascending aorta. It was discovered, and validated by several researchers that blood flow out of the left ventricle into the aorta is spiral in nature. In this study, a novel design in which internal profile of the cannula was made to induce spiral flow were tested by way of numerical simulation, and compared against existing commercial cannula. Three designs were tested, which differed in number of groove employed. Among the cannula model designs, cannula design with 4 grooves yielded the lowest value of maximum wall shear stress at testing tube with $3.778(\mathrm{~Pa})$ and highest value of area weighted helicity density at $11.829 \mathrm{~m} / \mathrm{s}, 40 \mathrm{~mm}$ from cannula tips. Overall, spiral cannula models showed high potential in inducing spiral flow, while the effect on blood hemolysis is acceptable.
\end{abstract}

\section{Introduction}

Arterial cannulation at the ascending aorta during the Cardiopulmonary Bypass (CPB) operation during open heart surgery via aortic cannula is used to supply oxygenated blood from Heart Lung Machine (HLM) to the patient body. However, the aortic cannula has the smallest cross section among the extracorporeal circuit which in turn produced high jet velocity when exiting the cannula tip [1]. The rapid and focused jet flow impinging on the inner aortic walls lead to 'sandblasting effect', characterized by arteries become narrowed and hardened due to excessive build up of plaque around the artery wall [2]. These event are attributed to atheromatous emboli generation and increasing the risk of stroke up to $25 \%[3]$.

Numerous study have been done to improve the aortic cannula and minimize flow complication on these design factors cannula length effect [4], cannula tip modification (multiple stream and dispersed stream [5,6]; and recently the design was directed to inducing spiral flow [7]. Blood flow in the thoracic has been shown to exhibit spiral flow characteristics physiologically [8]. There are published advantages of spiral flow characteristics in the thoracic aorta such as stabilizing the flow direction through curved pathway, reducing laterally direct force, reducing near wall turbulence, lower shear stress and oscillating stress near wall and also has possible tendency to prevent atherosclerotic plaque $[9,10]$. However there are still uncertainties which design is the most suitable to induce physiologically similar spiral flow. This study was carried out to determine whether the proposed novel design can induce spiral flow passively without undermining the cannula efficacy by comparison between several sets of cannula numerically. 


\section{Method}

Geometry modelling. The proposed novel designs were drafted by using computational aided design software; the cannula were modelled using SolidWorks 2013 (SolidWorks Corp. US) by varying the groove numbers (2, 3 and 4). The standard straight for adult cannula dimension (24 Fr; inner diameter, $8 \mathrm{~mm}$; total cannula length, $250 \mathrm{~mm}$ ) was used for all other purpose designs. Figure 1 shows the geometry and cross section of each cannula designs.
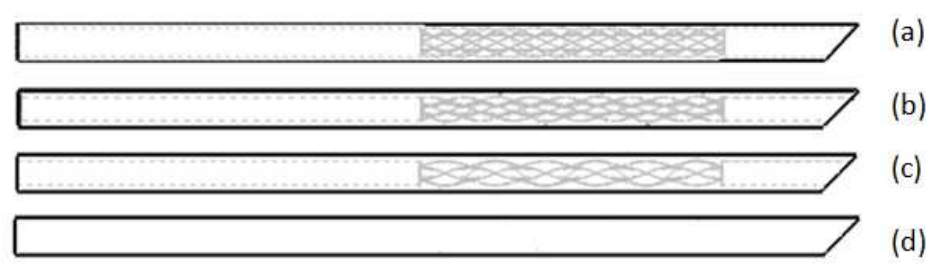

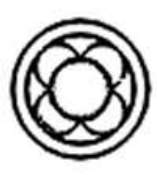

(a)

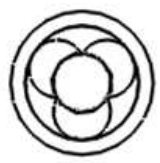

(b)

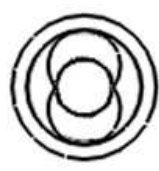

(c)

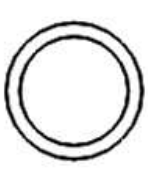

(d)

Fig. 1 The four cannula design models and cross section view (a) G4 (b) G3 (c) G2 (d) Standard

The novel internal groove length was set at $90 \mathrm{~mm}$ with 3 revolutions of $30 \mathrm{~mm}$ pitch length. Since the standard cannula insertion procedure at the ascending aorta is towards the aortic arc and nominal aorta diameter range between 24 to $26 \mathrm{~mm}$ [11], it was decided that the straight tube with $25 \mathrm{~mm}$ inner diameter and $250 \mathrm{~mm}$ length was used as representative of aorta to evaluate the flow output from the cannula. All models were attached at the straight tube as illustrated in figure 2, with an interval of $20 \mathrm{~mm}$ for ten was set for flow analysis.

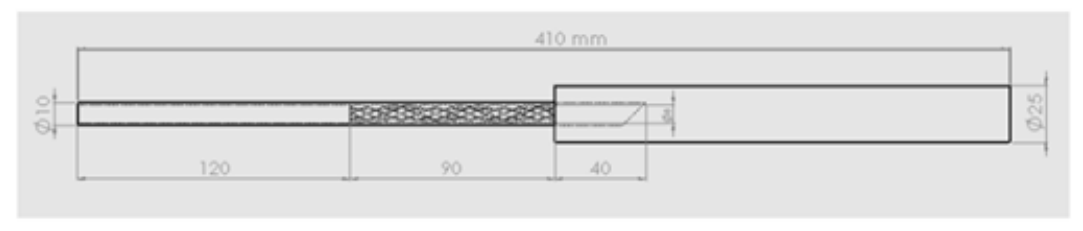

Fig. 2 The models geometry

Governing equation and boundary condition. In this study, all simulations assumed steady state and rigid wall. Rigid wall is feasible assumption during CPB situation since the flow was continuous flow [12]. Blood is considered as a Newtonian and incompressible flow with constant hemodynamic properties $\left(\rho=1050 \mathrm{~kg} / \mathrm{m}^{3}, \mu=0.00345 \mathrm{~N} . \mathrm{s} / \mathrm{m}^{2}\right.$ ) was employed and no-slip boundary condition were enforced at the vessel wall. This Newtonian blood assumption is acceptable since aorta is considered a large artery with shear rate of 300/s and blood viscosity approximately 3.5 centipoises or $0.0035 \mathrm{~Pa}^{*} \mathrm{~s}(45 \%$ heamatocrit) [13], and it also has been concluded that for high shear rates (above 100/s) in medium and large arteries, Newtonian blood model is good reasonable approximation [14]. The inlet flow rate was set as a uniform flow ranging from 1 to $6 \mathrm{~L} / \mathrm{min}$ and pressure at the outlet of the straight tube set at $16000 \mathrm{~Pa}(120 \mathrm{mmHg})$ to represent the pressure inside the aorta during systole. Commercial package ANSYS FLUENT 14.0 (Ansys. Inc., PA, USA) was used to solved this equation using finite volume method.

This study was similar to Avrahami et al. 2013; the Reynolds number within the straight tube was from 2511 to 15,14 , most of the study cases showed in the transitional zone of low Reynolds turbulence [11]. Therefore, the k- $\omega$ was selected as a turbulence model for all cases due better accuracy in transitional zone and better predictions for boundary layers with adverse pressure gradients. However, this type of turbulence model required very fine mesh close to the wall. By inserting inflation, mapped face meshing and edge sizing on the model as figure 2, the mesh size reached to $960 \mathrm{k}$ nodes and $4760 \mathrm{k}$ elements. 
Data Analysis. To evaluate the results of this study, the performance of spiral flow was evaluated using area-weighted helicity density on the straight tube. Helicity density has been proven adequate to describe the spiral flow in the aorta [15]. The formula as follows:

$$
\begin{aligned}
& H a=\frac{1}{S} \int H d d S \\
& H d=\vec{V} \cdot(\nabla \times \vec{V})
\end{aligned}
$$

Where $\mathrm{Ha}$ is the average helicity density, $\mathrm{Hd}$ is the helicity density, $\mathrm{S}$ is cross section area and $\mathrm{V}$ is velocity vector. Pressure drop from cannula inlet centre point to outlet centre point, pressure contour, velocity streamlines and wall shear stress (WSS) were also used as results outputs to delineate the flow behaviour of each cannula designs affected by the number of groove.

\section{Results}

Velocity Distribution. Figure 3 illustrates the velocity streamlines of all models at $5 \mathrm{~L} / \mathrm{min}$ inflow rate. The maximal flow velocity reached up to $3.726 \mathrm{~m} / \mathrm{s}$ mostly at the centreline of cannula models, and diffused when entering the straight tube. Models G2, G3 and G4 (spiral designs) showed visibly different streamline profile compared to standard design; spiral designs produced spiral/curly path meanwhile standard cannula produced a much more uniform path inside the straight tube. Among the spiral designs, G4 model seem to induce more complex flow when exiting the cannula tip. Since cannula tip was fix at $40 \mathrm{~mm}$ from the edge of straight tube, backflow obviously occurred in standard model due to pressure gradient between end of tube and cannula tip.

Pressure drop. The aortic cannula pressure drop was commercially used as an indicator to predict the flow behaviour and blood damage inside the cannula. Brodman et al., (1985), evaluated 29 different cannulae, and he concluded that a cannula can only be recommended for clinical used with pressure drop below $100 \mathrm{mmHg}$ at $4 \mathrm{~L} / \mathrm{min}$ to avoid excessive damage of blood elements[16]. Figure 4 illustrates graph relation between pressure drop and inlet flowrate. All spiral designs pressure drop were under acceptable limit of $80 \mathrm{mmHg}$. Despite that, pressure drop of spiral designs model was evidently higher than standard cannula model. This might due to reduction of cross sectional area of fluid domain where reduction of internal fluid domain area in the spiral cannula designs leading to increased pressure drop.

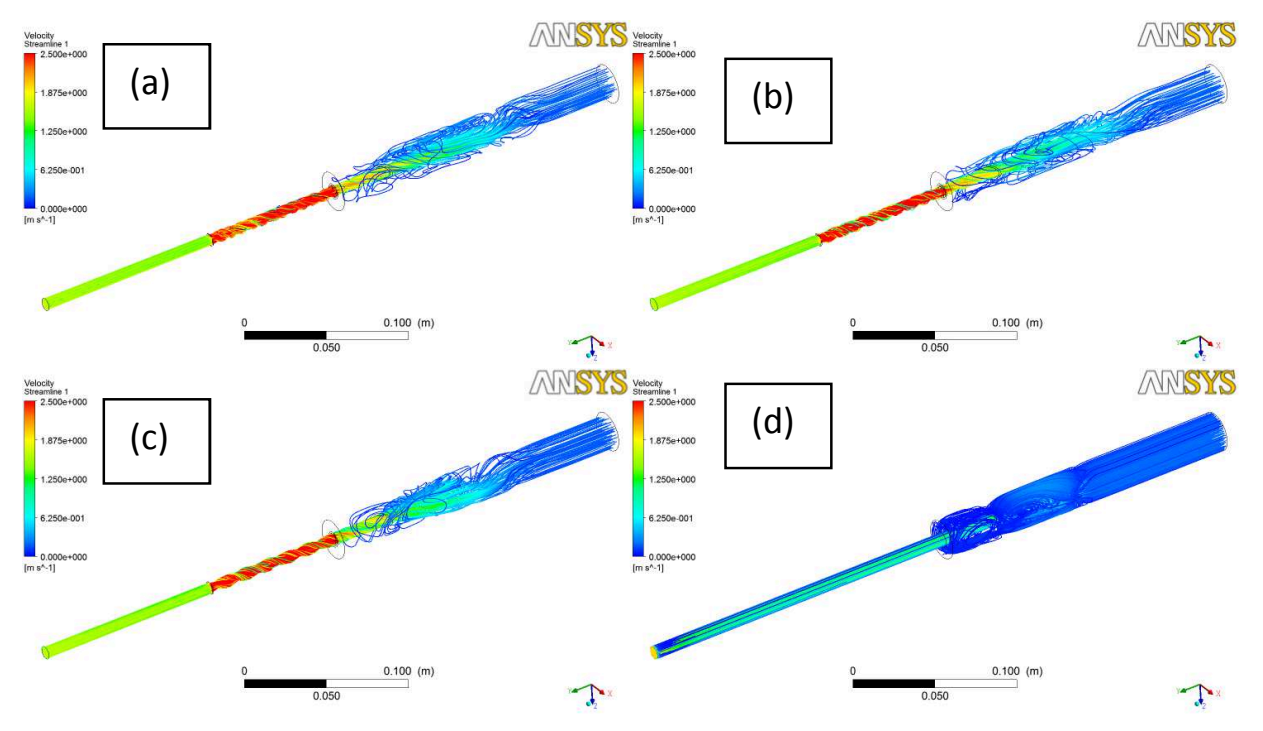

Fig. 3: Velocity streamlines of the models (a) G4 (b) G3 (c) G2 (d) Standard 


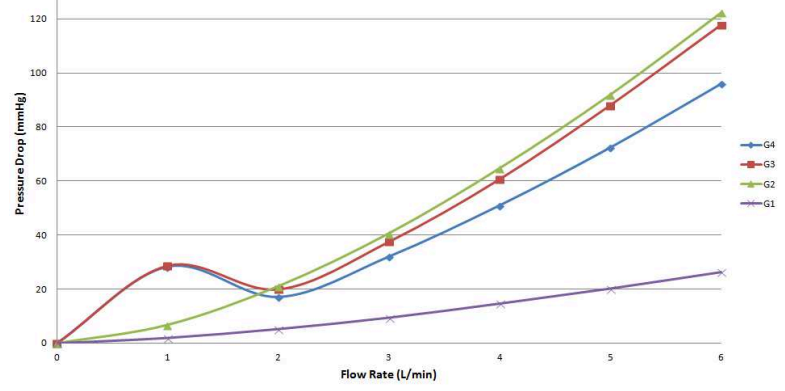

Fig. 4 Pressure drop versus inlet flow rate along the cannula tube.

Wall shear stress (WSS). Shear stress distribution on the straight tube wall is illustrated in Figure 5 was at $5 \mathrm{~L} / \mathrm{min}$. The maximum value yielded was $5.77 \mathrm{~Pa}\left(57.72 \mathrm{dyne} / \mathrm{cm}^{2}\right)$ model G2. Since upper limit of physiological WSS value in aorta $2 \mathrm{~Pa}\left(20 \mathrm{dyn} / \mathrm{cm}^{2)}\right.$ [17]. The $\mathrm{G} 2$ model had the lowest cross sectional area thus the out flow from G2 the highest velocity, meanwhile the critical value of shear stress that can cause blood cells hemolysis from the medical devices is $450 \mathrm{~Pa}(4500$ dyne $/ \mathrm{cm}^{2}$ ) [18], and only G4 model exceeded that limit. Table 1 shows the maximum and minimum value of all models. At tube wall, G4 yielded the lowest maximum value of WSS but highest at the cannula wall. It is evident that spiral designs cannula with groove profile needs to be improved further to ensure the WSS value for both regions within the cannula and in the test tube is within acceptable range.

Table 1 Maximum and minimum wall shear stress value at wall for each models.

\begin{tabular}{ccccc}
\hline & \multicolumn{2}{c}{ Tube Wall } & \multicolumn{2}{c}{ Cannula Wall } \\
\hline Model & $\begin{array}{c}\text { Maximum } \\
(\mathrm{Pa})\end{array}$ & $\begin{array}{c}\text { Minimum } \\
\times 10^{-4}(\mathrm{~Pa})\end{array}$ & Maximum $(\mathrm{Pa})$ & Minimum $(\mathrm{Pa})$ \\
\hline $\mathrm{G} 1$ & 4.261 & 1.810 & 171.117 & 12.178 \\
$\mathrm{G} 2$ & 5.772 & 2.298 & 447.134 & 0.491 \\
$\mathrm{G} 3$ & 5.107 & 1.100 & 394.068 & 0.410 \\
$\mathrm{G} 4$ & 3.778 & 3.703 & 450.255 & 0.201 \\
\hline
\end{tabular}

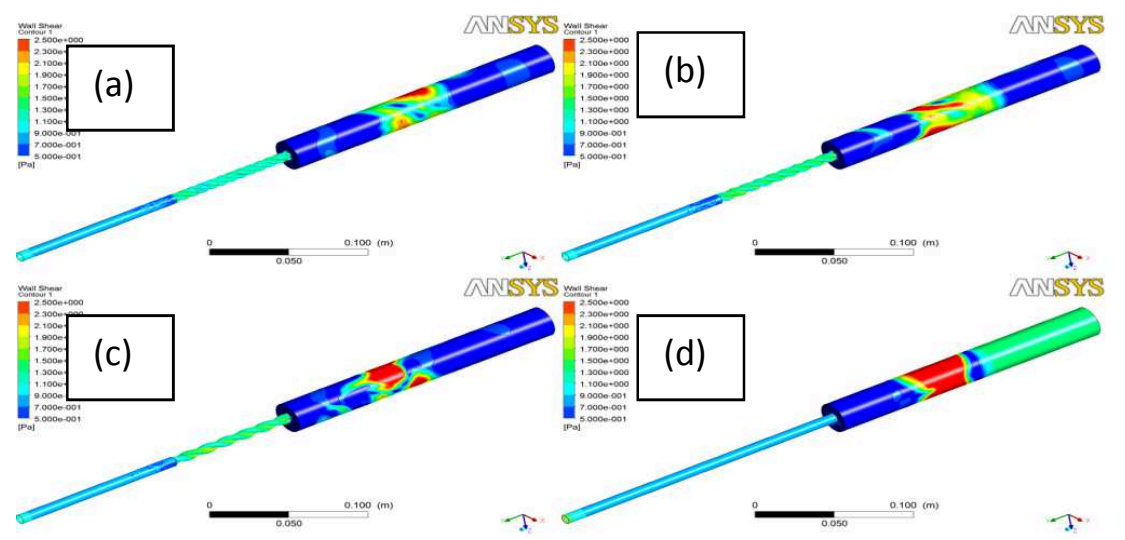

Fig. 5 Wall shear stress distribution on the straight tube wall (a) G4 (b) G3 (c) G2 (d) Standard

Helicity density. From the graph in Figure 6, helicity density is a reliable indicator for spiral flow in the aorta [15]. As illustrated in Figure 9, G1 had flat graph on every cross section obviously due to straight flow out of cannula tip. In general, all spiral cannula designs with internal groove profile cannula exhibited spiral flow, with G3 model yielded highest area-weighted average helicity value at $64.48 \mathrm{~m} / \mathrm{s}^{2}$ from first until third cross section. However, for all spiral models, the spiral flow only maintained until around $60 \mathrm{~mm}$ from the cannula tip before diminishing. 


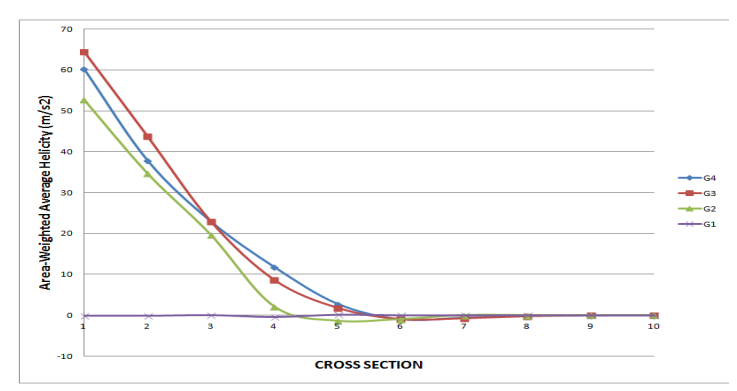

Fig. 6 Area-weighted Average Helicity graph

Conclusion. This study provided showed the effect of groove profile inducing spiral flow. There were three different designs, with varying number of grooves from two to four. In general, spiral designs cannula showed better performance compared to the standard cannula design in term of wall shear stress distribution; it was found that G4 yielded the lowest WSS maximum value within the straight tube. Even though the velocity magnitude for spiral designs was higher than standard design inside the cannula, the velocity magnitude at the centerline of the models was almost the same value when exiting the cannula tips for all models. Spiral designs had around $30 \%$ increment of pressure drop compared to standard designs but still under acceptable limits at flowrate $4 \mathrm{~L} / \mathrm{min}$. Helicity density analysis shows promising results, the designs proposed here manage to induce spiral flow. However, there are still rooms to improve to prolong the helical flow, and to reduce WSS.

Acknowledgment. This study was supported in part using the Ministry of Education Malaysia under grant no. G0071. The authors wish to thank Institut Jantung Negara (IJN) for their support in providing clinical support.

Conflict of Interest. We hereby declare that no conflict of interest exists in our work.

\section{References}

[1] R. C. Groom, A. G. Hill, B. Kuban, W. Oneill, B. F. Ak1, A. M. Speir, J. Koningsberg, G. T. Sprissler, M. Shakoor, P. S. Massimiano, N. A. Burton, R. A Albus, Q. Macmanus, and E. A. Lefrak, “Aortic cannula velocimetry,” Perfusion, vol. 10, no. 3, pp. 183-188, May 1995.

[2] A Grossi, M. S. Kanchuger, D. S. Schwartz, D. E. McLoughlin, M. LeBoutillier, G. H. Ribakove, K. E. Marschall, a C. Galloway, and S. B. Colvin, "Effect of cannula length on aortic arch flow: protection of the atheromatous aortic arch.," Ann. Thorac. Surg., vol. 59, no. 3, pp. 7102, Mar. 1995.

[3] S. Katz, P. a Tunick, H. Rusinek, G. Ribakove, F. C. Spencer, and I. Kronzon, "Protruding aortic atheromas predict stroke in elderly patients undergoing cardiopulmonary bypass: experience with intraoperative transesophageal echocardiography.," J. Am. Coll. Cardiol., vol. 20, no. 1, pp. 70-7, Jul. 1992.

[4] A Grossi, M. S. Kanchuger, D. S. Schwartz, D. E. McLoughlin, M. LeBoutillier, G. H. Ribakove, K. E. Marschall, a C. Galloway, and S. B. Colvin, "Effect of cannula length on aortic arch flow: protection of the atheromatous aortic arch.," Ann. Thorac. Surg., vol. 59, no. 3, pp. 7102, Mar. 1995. 
[5] Joubert-Hübner, A. Gerdes, P. Klapproth, K. Esders, J. Prosch, P. Henke, G. Pfister, and H. H. Sievers, "An in-vitro evaluation of aortic arch vessel perfusion characteristics comparing single versus multiple stream aortic cannulae.," Eur. J. Cardiothorac. Surg., vol. 15, no. 3, pp. 359-64, Mar. 1999.

[6] M. Minakawa, I. Fukuda, J. Yamazaki, K. Fukui, H. Yanaoka, and T. Inamura, "Effect of cannula shape on aortic wall and flow turbulence: hydrodynamic study during extracorporeal circulation in mock thoracic aorta.," Artif. Organs, vol. 31, no. 12, pp. 880-6, Dec. 2007.

[7] P.G. Menon, J.F. Antaki, Akif Undar, and Kerem Pekkan, "Aortic Outflow Cannula Tip Design and Orientation Impacts Cerebral Perfusion During Pediatric Cardiopulmonary Bypass Procedures," 2013.

[8] M. Tanaka, T. Sakamoto, S. Sugawara, H. Nakajima, T. Kameyama, Y. Katahira, S. Ohtsuki, and H. Kanai, "Spiral systolic blood flow in the ascending aorta and aortic arch analyzed by echodynamography.," J. Cardiol., vol. 56, no. 1, pp. 97-110, Jul. 2010.

[9] F. Linge, M. A. Hye, and M. C. Paul, "Pulsatile spiral blood flow through arterial stenosis.," Comput. Methods Biomech. Biomed. Engin., no. March, pp. 37-41, Mar. 2013.

[10] P.A. Stonebridge, F. Vermassen, J. Dick, J. J. F. Belch, and G. Houston, "Spiral laminar flow prosthetic bypass graft: medium-term results from a first-in-man structured registry study., Ann. Vasc. Surg., vol. 26, no. 8, pp. 1093-9, Nov. 2012.

[11] I. Avrahami, B. Dilmoney, O. Hirshorn, M. Brand, O. Cohen, L. Shani, R.-R. Nir, and G. Bolotin, "Numerical investigation of a novel aortic cannula aimed at reducing cerebral embolism during cardiovascular bypass surgery.," J. Biomech., vol. 46, no. 2, pp. 354-61, Jan. 2013.

[12] P. G. Menon, N. Teslovich, C.-Y. Chen, A. Undar, and K. Pekkan, "Characterization of neonatal aortic cannula jet flow regimes for improved cardiopulmonary bypass.," J. Biomech., vol. 46, no. 2, pp. 362-72, Jan. 2013.

[13] T. G. Papaioannou and C. Stefanadis, "Vascular wall shear stress: basic principles and methods.," Hellenic J. Cardiol., vol. 46, no. 1, pp. 9-15, 2005.

[14] A. D. Caballero and S. Laín, "A Review on Computational Fluid Dynamics Modelling in Human Thoracic Aorta," Cardiovasc. Eng. Technol., vol. 4, no. 2, pp. 103-130, Apr. 2013.

[15] X. Liu, Y. Fan, and X. Deng, "Effect of spiral flow on the transport of oxygen in the aorta: a numerical study.," Ann. Biomed. Eng., vol. 38, no. 3, pp. 917-26, Mar. 2010.

[16] R. Brodman, H. Siegel, M. Lesser, and R. Frater, "A Comparison of Flow Gradients across Disposable Arterial Perfusion Cannulas," Ann. Thorac. Surg., vol. 39, no. 3, pp. 225-233, Mar. 1985.

[17] Nandini Duraiswamy, Richard T Schoephoerster, "NIH Public Access," J. Biomech. Eng., vol. 131, no. 6, pp. 1-22, 2009.

[18] R. Paul, J. Apel, S. Klaus, F. Schügner, P. Schwindke, and H. Reul, "Shear stress related blood damage in laminar couette flow.," Artif. Organs, vol. 27, no. 6, pp. 517-29, Jun. 2003. 